\title{
Pedagogy for Mobile ICT Learning Using Video-Conferencing Technology
}

\author{
Dragana Martinovic \\ University of \\ Windsor, \\ Windsor, ON, \\ Canada
}

\author{
Timothy Pugh \\ Grand Erie DSB, \\ Brantford, \\ ON, Canada
}

\author{
Jelena Magliaro \\ University of \\ Windsor, \\ Windsor, ON, \\ Canada
}

dragana@uwindsor.ca timothy.pugh@granderie.ca jelena@uwindsor.ca

\begin{abstract}
The objective of this paper is to describe the pedagogical and related organizational approaches implemented for mobile learning utilized between a school board and its partnered institutions: Faculties of Education and research institutes. While the two learning events described here were intended to provide mobile ICT-enabled and collaborative learning opportunities for students, the research component of the project was designed to explore the adoption of video-conferencing technology and other collaborative Information and Communication Technologies (ICT) amongst educators. The objective was to evaluate, from the educators' perspectives, the benefits and obstacles associated with the use of emerging technologies within daily, classroom pedagogy. In order to do so, the authors have chosen two learning events that are very different in terms of their targeted populations, organizational complexity, and pedagogical goals. These learning events were also reflected upon by three in-service teachers from the school board (participants in one of the events), as well as five pre-service teachers, from one of the partner universities, who were observers of the events. A qualitative data analysis process revealed that these two groups have respectively realist and idealist views on ICT integration within schools. The authors concluded that ICT-enabled learning is best adopted through lived experiences and that those may be used to initiate and maintain paradigmatic transition between the various stages of learning on the teacher development continuum (idealist $\rightarrow$ realist $\rightarrow$ realistic-idealist), a process by which teachers become inspired users and promoters of innovative tools for mobile ICT learning in the classroom.
\end{abstract}

Keywords: ICT-enabled learning, pre-service teachers, in-service teachers, video-conferencing, ICT integration, mobile technologies, teacher development continuum.

Material published as part of this publication, either on-line or in print, is copyrighted by the Informing Science Institute. Permission to make digital or paper copy of part or all of these works for personal or classroom use is granted without fee provided that the copies are not made or distributed for profit or commercial advantage AND that copies 1) bear this notice in full and 2) give the full citation on the first page. It is permissible to abstract these works so long as credit is given. To copy in all other cases or to republish or to post on a server or to redistribute to lists requires specific permission and payment of a fee. Contact Publisher@InformingScience.org to request redistribution permission. 
There is a need to re-conceptualise learning for the mobile age, to recognise the essential role of mobility and communication in the process of learning, and also to indicate the importance of context in establishing meaning, and the transformative effect of digital networks in supporting virtual communities that transcend barriers of age and culture. (Sharples, Taylor, \& Vavoula, 2005, para. 1)

\section{Introduction}

Building upon the opening quote from Sharples, Taylor, and Vavoula (2005), we embark upon the task of illustrating the pedagogy and organization suitable for mobile, Information and Communication Technologies (ICT)-enabled learning. The instances explored in this paper utilize video-conferencing technology as a significant finishing step for each learning opportunity. Such consideration of mobile learning extends the practical integration of education technology into daily curriculum.

The term 'mobile learning' has been in use from 1967, but its meaning has changed considerably since then (see, for example Laouris \& Eteokleous, 2005). Today, different interpretations emerge, ranging from a notion that mobile learning mostly encompasses learning achieved through the use of mobile devices and wireless transmission (Milrad, 2003; Nyiri, 2002), to the idea that it involves education that is produced, circulated, and consumed over a network (Polsani, 2003). For Nyiri (2002), mobile learning "arises in the course of person-to-person mobile communication," while for Sharples (2005), its major feature is in "continual communication with and through technology" (p. 7). This is similar to how "ICT-enabled learning" is defined. Punie (2007) states that, "[i]t is almost impossible to imagine a future learning environment without some sort of ICT, either at the forefront or in the background" (p. 186). In Punie's vision, ICT-enabled learning is "one of the key applications for the development of the information society" (p. 195). His opinion is that this is so because such learning happens in a social context and enables synchronous communication between learners and sites.

Up to the recent past, mobile devices and wireless transmission were not suitable for delivering rich multimedia content. It is then not surprising that "[v]ideoconferencing,... which requires simultaneous decoding and encoding in real-time, poses still a grand challenge to the mobile world" (Cycon, Schmidt, Hege, Wählisch, \& Palkow, 2007, p. 21). However, this situation may soon change and new pedagogies need to be developed and mastered in order to be able to take advantage of these new learning opportunities. In this paper, the authors purpose to walk the reader through the painstakingly detailed process of developing a responsive pedagogy, as well as to introduce the reader to educators who are willing to implement such a process. In so doing, we use the terms "mobile" and "ICT-enabled" together, to describe the process of transferring rich multimedia learning content at distance with a support of wireless and/or wired computer networks.

In this case, video-conferencing technology is employed so that learners, unimpeded by distance or grade level, can interact and participate in synchronous, real-time, virtual educational events. Furthermore, if recorded and then used asynchronously for future reflection, this kind of learning is denoted by "the [learner's] ability to move backward and forward through different stages of a [learning event]" (Cuthell, 2006, p. 101), whereby the learner can further evaluate and reflect upon the event's various components. However, the difficulties of gaining skills in effective pedagogy and associated organizational practices for successful video-conference-based learning may seem significant to those teachers who are neither personally comfortable with nor professionally convinced of the related benefits of ICT-enabled learning. These areas of concern would undoubtedly include the considerable material preparation and organizational time spent outside the classroom environment prior to the learning events themselves. Such perceptions may well induce the technological inertia for which some school systems have long been known. In fact, 
Cuthell (2006) views schools as supertankers, where "a change of direction requires a considerable amount of forward planning before it takes effect" (Cuthell, 2006, abstract). Such forward planning is demonstrated in this paper, as it includes the pre-event organizational aspects, as well as the carefully planned pedagogy that ultimately culminates in the video-conference-based learning events.

Here, we apply the notion that, besides appropriate access and support, the modeling of ICT use within the classroom is a key component in the development of effective ICT use (Hammond et al., 2009). Furthermore, Hammond et al. emphasize, especially in the context of pre-service education, the importance of "the belief that ICT could make a positive difference to teaching and learning and a willingness to 'learn by doing'" (p. 59). In the following section, we describe two pedagogical approaches that involve ICT-enabled, video-conference-based learning, utilized between a school board and its partner institutions, where elementary and high school students, preservice teachers, in-service teachers, educational researchers, and experts were connected to support and create new learning. This endeavour was part of a collective effort to enhance the daily student experience within a context of collaborative research. By so doing, we model the pedagogy involved in mobile ICT-enabled learning which has the potential to make a positive and sustainable impact on both emerging and practicing educators when collaborative input from various partners is synergistically employed.

\section{Outline of Paper}

We begin this paper with a brief historical overview of this project's origins, followed by detailed descriptions of two ICT-enabled learning events, replete with the necessary pedagogy, organization, as well as associated resources, both technological and human. From there, we move the reader through the employed methodological and data-collection tools. This is followed by brief information on data analysis and substantial report on related findings. Pertinent conclusions are then explored with a view to future work.

\section{A Brief History}

This report builds upon the evidence and research findings resulting from the convergence of two longitudinal projects, (i) Martinovic's Helping Teachers to Become Agents of Change and (ii) Pugh's Virtual GrandE Communication Literacy Project. The former project is more oriented toward pre-service programs, with the intent to annually follow the development of ICT skills and attitudes of pre-service teachers in the Faculty of Education. Comparatively, Virtual Grand $\varepsilon$ is a cross-curricular, cross-grade, inter-school, system-wide literacy initiative aimed at enhancing student learning and achievement through the deployment of embedded collaborative technology tools into the daily teaching and learning experiences of in-service teachers and their students. The intent of both projects, and therefore of the resulting collaboration, is to use existing and emerging technologies (i.e., video-conferencing, SmartBoards, video cameras, laptops, and integrated webcams) to enable students and teachers from all academic streams and groupings to create authentic forums for the exchange of ideas, thus providing them with novel educational opportunities through specific learning events (Martinovic, Magliaro, \& Pugh, 2009). These forums are facilitated through a contextualized approach to each learning site. Participating teachers ground the ICT-based learning events upon their daily teaching routines and curricular learning targets. This process results in engaging, student-driven learning events that are centered upon the needs of the specific teachers and students involved in each particular interaction. These learning forums serve a wide gamut of student groupings per event, ranging from single-site, single-grade classroom groupings of 15-30 students to multiple-site, multi-grade learning opportunities of over 1100 participating students. 


\section{Description of Learning Events}

In order to further clarify our work, here we provide examples of two very different learning events: (i) Egg Drop Experiment and (ii) Canadian Space Agency Learning Event. After outlining the pedagogy that guided each of the events, we discuss both the organizational steps taken and the technological resources involved in the events.

\section{Learning Event \#1: Egg Drop Experiment}

The Egg Drop Experiment served as the culminating assessment task for a unit on Air and Flight from the Grade 6 Ontario Science and Technology curriculum ("The Ontario Curriculum," 2007). In it, the students were involved in planning, constructing, and testing a device to demonstrate their understanding of the properties of air and the principles of flight. The goal was to create a device that would safeguard a raw egg from a drop of 2.5 meters onto a cement floor. This culminating task took the place of a formal pen and paper test. Students were organized into small working task groups. The activity was preceded by a series of class studies and discussions, hands-on experiments, movies on flight (i.e., historical footage of Wright Brothers), movies on military flight and the Canadian Space Program, as well as Internet-based research activities. Since the Egg Drop Experiment was to contain detailed instructions (see Appendix A), the students practiced procedural writing (involving paper plane construction) when they participated in a classroom-based Air Show competition. The integration of curriculum was organized so that this Science unit was informed by other core subject areas: English-oral-visual communication, media literacy, reading, and procedural writing; and Mathematics - measurement, geometry (angles), and algebra. In fact, all subjects were integrated into this curricular unit to some degree with the exception of French and Physical Education (because the teacher did not teach these subjects).

Throughout their studies within the unit, the students prepared a list of "burning questions" that they could not effectively answer through their standard classroom-based research methods. The students and the teacher then further identified some of these questions based upon criteria that students felt were of importance like, "Have I found out the answer to this question in any other way that makes sense to me?"; and, "Do I need this question answered in order to fully understand the properties of air and the principles of flight?" The resultant list of questions was then compiled and prepared so that students were able to pose them to an air and flight expert during the culminating task.

The day of the culminating learning task started at 9 AM, as usual. From 9 to 9:30 AM, students reviewed written and verbal instructions and received the resources ${ }^{1}$ provided for the creation of their devices. The students worked on the creation task from 9:30 to 11:30 AM. At approximately $11 \mathrm{AM}$, the classroom was connected via synchronous video-conferencing technology with University of Windsor, where a group of pre-service teachers and researchers observed the class at work for an hour. At 12:30 PM, the classroom was also connected via synchronous videoconferencing to an expert at the University of Toronto's Aeronautical Engineering Department. The expert first gave a short presentation on the properties of air and the principles of flight and then answered students' questions. After the general question and answer time, the expert then gave suggestions for improvement to the students after each task group visually presented their

\footnotetext{
${ }^{1}$ A meter of masking tape; a meter of duct tape; two paper plates; two Styrofoam cups; a handful of cotton balls; five q-tips; two types of strings (i.e., cotton and nylon); wooden popsicle sticks; three pieces of wooden dowling; six shower curtain rings; five nail polish toe separators; five wooden close pins; five Styrofoam balls; three pieces of letter-size paper; a plastic bag and one raw egg.
} 
devices to him over live video. After obtaining the expert's feedback, the children performed any necessary modifications and then tested their structures through the "egg drop experiment" protocol (see Figure 1).

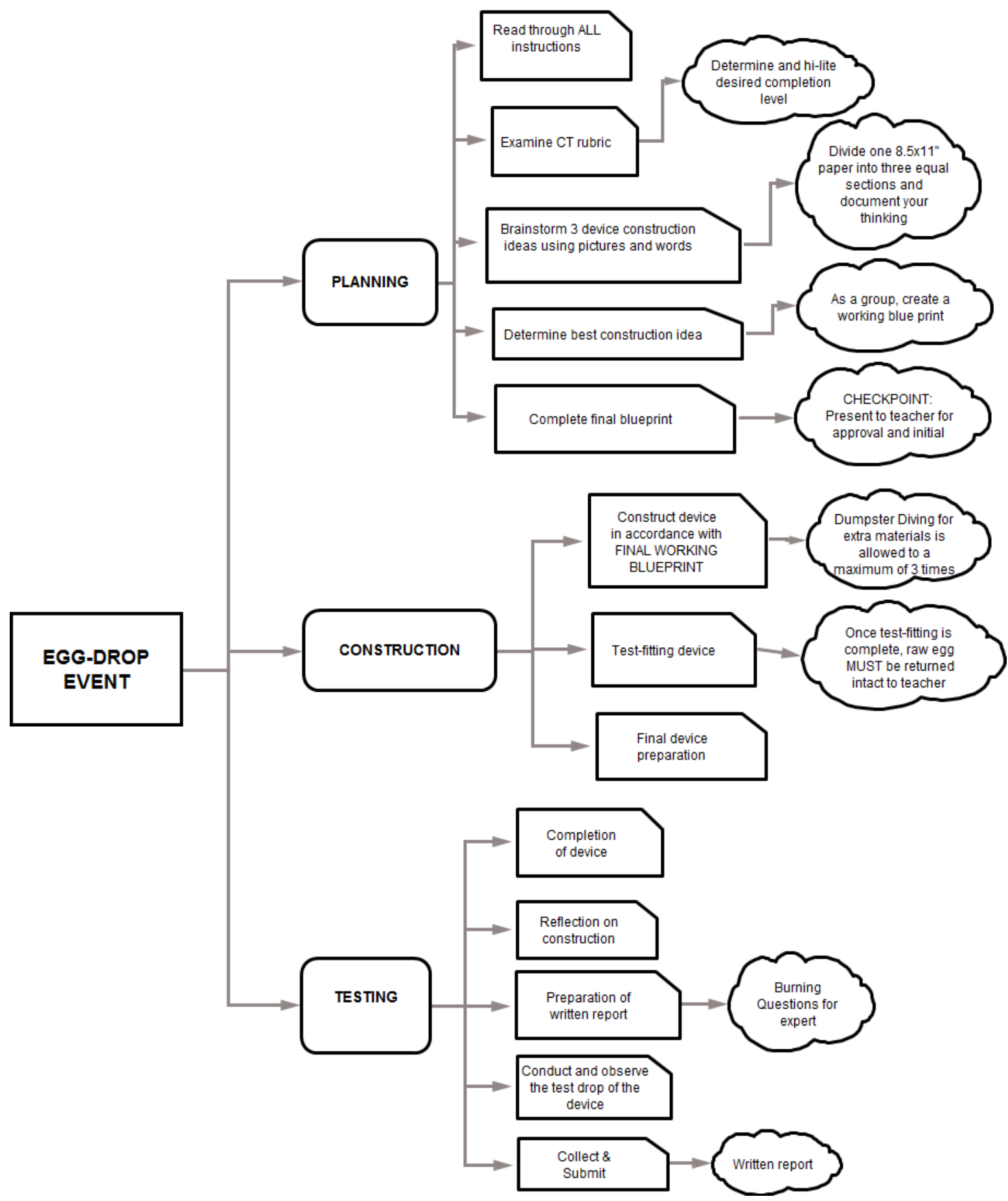

Figure 1. The Structure of the Egg Drop Experiment. 


\section{Organizational aspects}

In keeping with effective pedagogical practice, the teacher planned this unit beginning with the end in mind ("The Ontario Curriculum," 2007). From beginning to end, this unit on Air and Flight took approximately 6 weeks to complete. The curriculum elements, as previously listed, were integrated as part of the daily learning; but, the video-conferencing component needed to be deliberately planned and then added to the frame of the culminating experience. The teacher called upon another partner organization, VROC (Virtual Researcher on Call), which arranged for the remote access to the expert. In addition to the teacher, the class of 24 elementary students, and the remote expert based at University of Toronto, three parents, one pre-service teacher from Nipissing University, and one teacher consultant from the school board were also involved in the actual Egg Drop culminating event. The event was organized in the robotics lab of another school due to the fact that there was more physical space within which students could interact and work. Students and teachers were bused there at minimal expense to students. In order to facilitate this event, the teacher needed to obtain: Principal's permission, parents' permissions for videotaping, as well as standard field trip permission forms. The school secretary booked the bus, while the teacher booked the lab and the video-conferencing unit centrally within the board system.

At University of Windsor, the event was advertised amongst the pre-service teachers. Necessary permissions for data collection were obtained, the video-conferencing room and equipment were booked, and an IT technician was made available during the actual event.

This event was locally supported (at the school board level) by the Supervisor for IT Infrastructure and an IT technician. Remote support was offered by both Sheridan College, which served as a host site for this event through their codian bridge, and also by the University of Toronto where IT technical personnel with expertise in video-conferencing were made available.

\section{Technology}

One Polycom Viewstation video-conferencing camera, one mini-DV video camera, one iBOOK and one iSIGHT camera were used at the robotic lab - school site. The organizers used Skype, cell phones and text messaging to communicate prior/during the event and as an alternative option in the event that the virtual connection went down.

\section{Learning Event \#2: Canadian Space Agency}

This activity was done on a much larger scale. The intent was to organize a multi-targeted learning event for students in Grades 4-12, helping them to explore careers such as engineering and to learn about the International Space Station, as well as Canadian contributions to it. During this event, more than 1200 students and 50 teachers from the School Board were connected via real time video with an expert from the Canadian Space Agency. This expert was located at one school within the board which was in turn connected with two other participating schools, as well as with the Faculty of Education's video-conferencing theatre at Nipissing University.

Since both elementary and secondary students participated in this event, it was important that all curricular elements were addressed in practical ways. This event was linked to specific aspects of the Ontario Elementary Science Curriculum, such as the study of space and the characteristics of planets, as well as overriding curricular and learning ideas like eco-research and environmental stewardship. The following items were addressed: Careers (engineering), Canadian contributions to the International Space Station; Canadian innovations in science (Canadian Space Agency program); marketing (Canadian innovation) careers and law (international cooperation); guidance (careers); applied science; Physics; as well as eco-research and environmental stewardship.

Each participating teacher had to send 10 questions created by his or her students to the Event Organizing Committee. Out of these, 1-2 were selected per teacher. These questions were then 
compiled according to video-conferencing site, selected for quality, and then sorted again for quantity. Following this, a decision was made regarding which of the compiled questions would be presented. This decision in turn dictated which schools at the various video-conferencing sites would be allowed to designate student speakers. The final questions were then communicated back to the originating teachers. Subsequently, the teachers were asked to choose and prepare the students to read the questions and interact with the expert during the learning event.

\section{Organizational aspects}

In addition to the Supervisor of Infrastructure, board support at the local level, assistance for this event was also provided by the Manager of IT Services, three school principals (from hosting schools), Director of Nipissing University, Event Organizing Committee, and three IT technicians. Remote support was provided by both a local Internet service provider, who supplemented bandwidth, as well as by Polycom Canada, which sent an engineer, one sales representative, as well as one educational support person to check the network and make recommendations to the school board IT personnel. All three individuals from Polycom Canada stayed throughout the event. The coordinating teacher of the learning event initiated and maintained formal contact with Canadian Space Agency, whose representative helped to frame the contributions of its expert for this event. The Canadian Space Agency sent tokens for all of the 1200 participating students and teacher support packets prior to event.

Students and teachers gathered in one of four locations for this special event - gyms in three schools (capacity of 500, 350, and 350 students) and Nipissing University lecture theatre (capacity 150 students). Prior to the event, the participating teachers were responsible for the distribution, collection, and collation of Student Permission Forms; the creation of "burning questions" (10 per class); the decision on three most pertinent questions from list, and the designation of three possible class representatives who were to present the final questions. Since this event involved multiple sites and about 1200 individuals, it had to be meticulously organized (see Appendix B).

On the day of the event, the expert spoke for about 40 minutes about careers (specifically engineering), Canadian contributions to the International Space Station, as well as highlights, challenges, and an overview of her position at Canadian Space Agency. This presentation was followed by open microphone sessions at each remote site according to a set schedule, maintained by teachers from the Organizing Team, who acted as the video-conferencing site moderators (see Figure 2).

These two learning events, referenced as "Egg Drop" and "Canadian Space Agency," were recorded and used asynchronously to collect data from pre-service teachers. The in-service teachers, who brought children to the Canadian Space Agency Learning Event, were another target population for this study. 


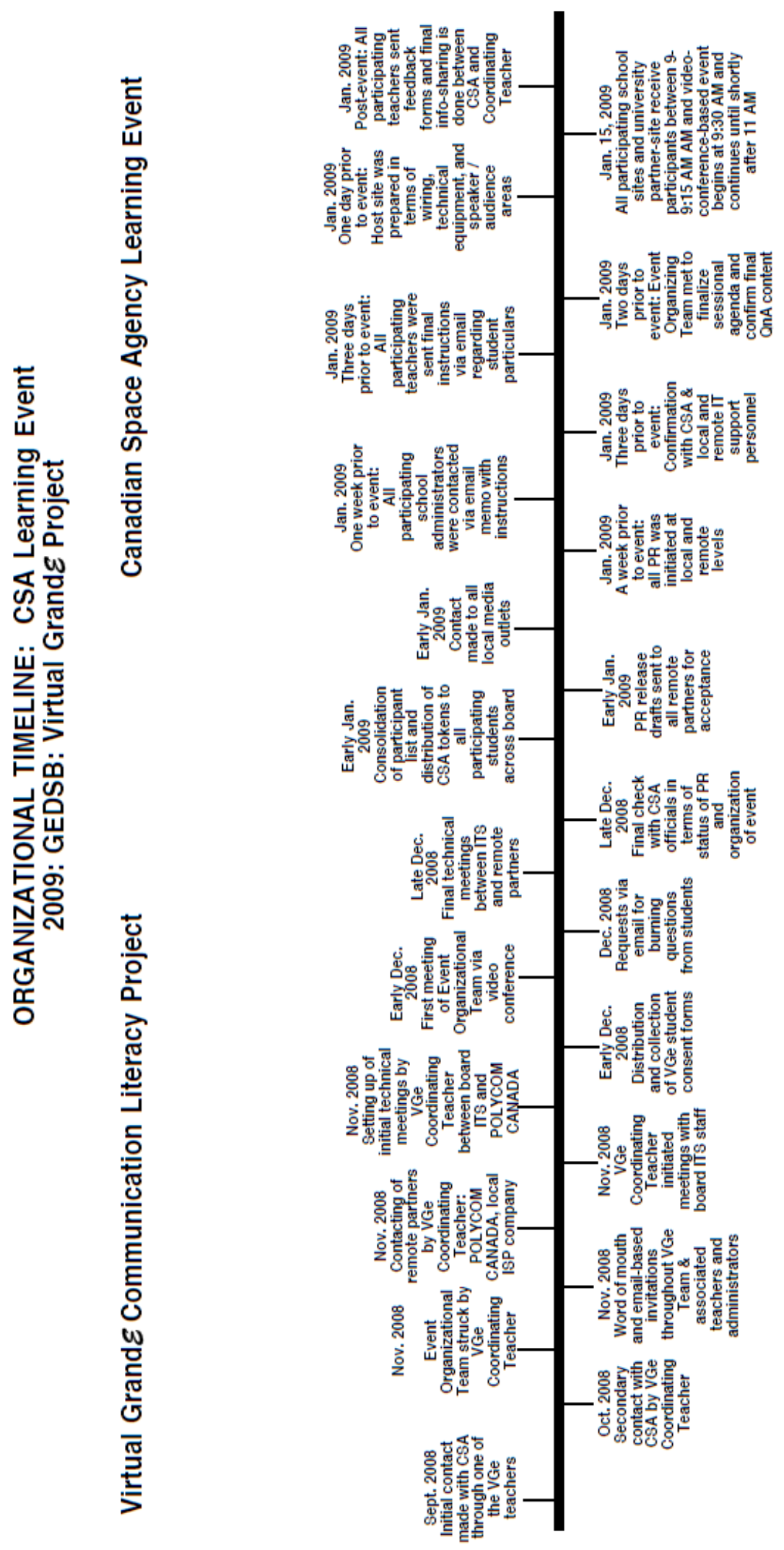

Figure 2. Organizational timeline for the Canadian Space Agency event. 


\section{Methodology}

This research is situated within Huberman's (1989) notion of "looking with both eyes," wherein one uses "two simultaneous lenses - the positivist and the interpretivist" (Cousins \& Simon, 1996, p. 201). By developing strong, sustained, and interactive links between research and practice communities (Cousins \& Leithwood, 1993) and by analyzing technology for mobile ICTenabled learning holistically, we hope to better understand the context of school activities that seek to embed the use of ICT into their daily learning environments.

\section{Data Collection Methods}

In accordance with our research methodology, we used various data collection methods. After the Canadian Space Agency learning event, participating in-service teachers were asked to do a survey on the adoption of ICT, to place themselves on the Use of an Innovation 8-level Scale, and also to provide qualitative feedback on the event itself (see Figure 3). In this feedback, besides background information, the in-service teachers categorized the learning event as useful or not useful for students and also for themselves, as learners. They were invited to elaborate upon the barriers that they perceived would be necessary to navigate if they were to run these events independently. In addition, the in-service teachers reflected on the benefits for learning they witnessed or observed during the events.

0. Non-use: Little or no knowledge of ICT in education, no involvement, doing nothing to become involved.

1. Orientation: Seeks or acquires information about ICT in education.

2. Preparation: Prepares for the first use of ICT in education.

3. Mechanical Use: Focuses on the short-term, day-to-day use of ICT with no time for reflection.

4. A. Routine: Feels comfortable using ICT in education, no effort to improve it or its consequences.

4. B. Refinement: Varies the use of ICT in education to maximize benefits.

5. Integration: Combines efforts with related activities of other teachers to achieve impact in the classroom.

6. Renewal: Reevaluates the quality of use of ICT in education, seeks major modifications, examines new developments in the field, and explores new goals.

Figure 3. The Use of an Innovation Scale, based on Griffin and Christensen (1999).

With pre-service teachers, we used pre- and post-intervention surveys, in which we asked them to place themselves on a Stages of Adoption of Integrated Technologies 6-level Scale (see Figure 4). Together with the pre-intervention survey, the participants provided background information and answered the revised Teachers' Attitudes toward Information Technology (TAT) (Knezek \& Christensen, 1998, as given in Knezek, Christensen, Miyashita, \& Ropp, 2000) survey.

The intervention consisted of three focus group meetings, wherein the pre-service teachers viewed video-taped footage of three previously organized video-conference-based learning events (two of which are described in the earlier text), and then had the opportunity to discuss the events and to answer probing questions from the questionnaire.

The participants evaluated each event based on its (a) interactivity (i.e., deliberate fostering of multi-layered, purposeful communication within the context of learning), (b) dynamics (i.e., the deliberate engagement of ALL learners within the context of the event through learner-driven 
activities), (c) dialogue-based learning (i.e., the deliberate validation of student-learners through one-to-one interaction with more advanced learners-experts), and (d) information sharing (i.e., the deliberate sharing of knowledge within the learning context so that each participant's individual level of literacy is increased). In addition, the pre-service participants listed the barriers they perceive in using such technology or in participating in such events.

1. Awareness: Aware that integrated technology tools exist but has not used them; perhaps even avoids them.

2. Learning the process: Trying to learn the basics; often frustrated using integrated technologies; lacks confidence.

3. Understanding and application of the process: Beginning to understand the process of using integrated technologies; can think of specific tasks in which they might be useful.

4. Familiarity and confidence: Starting to feel comfortable using integrated technologies for specific tasks.

5. Adaptation to other contexts: Thinks about integrated technologies as learning tools; no longer concerned about them; can use them in many applications and as instructional aids.

6. Creative application to new contexts: Able to use integrated technologies in an instructional way to integrate curriculum.

Figure 4. Stages of Adoption of Integrated Technologies Scale (based on Christensen, 1997).

\section{Data Analysis}

Quantitative data from the surveys were coded and analyzed using the SPSS 17 software. Qualitative data from the surveys and focus group meetings were organized into a table format within Excel and summarized. A small sample of participants (3 in-service and 5 pre-service) did not provide for extensive statistical analysis, but served as a useful trial of measurement tools and data collection techniques. In addition, the contrast and comparison of findings helped us to visually conceptualize the Use of Innovation and Stages of Adoption Scales.

\section{Findings}

\section{Data Gathered From In-Service Teachers}

\section{Level of innovation use}

The three participant in-service teachers conveniently cover the range of demographic options: two males (Tom and Ed) and one female (Sara). Tom and Ed had more than 15 years of teaching experience, while Sara had somewhat less teaching experience (6-10 years). Male participants taught in grades 7 and 8, whereas Sara was a junior teacher (grades 4-6). All three teachers used very little technology in their daily routines (about 1 hour/week) and considered themselves to be self-taught in this regard. Ed even described his experience with computers as, "I try to avoid using a computer and I don't plan to use it anytime soon." Figure 5 shows where these teachers were situated on the Use of an Innovation scale (teachers' names are fictitious).

Conceptually, the researchers organized the 8-level scale into three areas, namely, change of attitude (toward ICT), application (of ICT), and sophistication (in use of ICT). The in-service teachers' positioning on the scale presented Ed as not yet in the change of attitude stage, where teachers start showing interest for learning about technology and its use in class-based learning. Sara 
was clearly in the application stage where she is becoming skilled enough to start using technology mechanically and is looking into the pedagogical benefits, while Tom was embarking on the sophistication stage, where he is open for experimentation and new creative challenges in technology use.

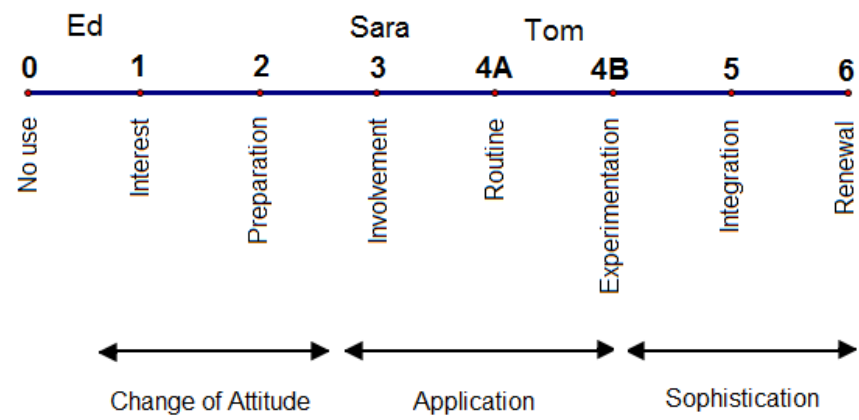

Note: Ed is between 0 and 1; Sara is at level 3; while Tom is between $4 A$ and $4 B$.

Figure 5. Position of the three in-service teachers on the Use of an Innovation Scale.

\section{Perceived barriers and benefits in organizing ICT-enabled learning events}

The in-service teachers found the video-conferencing event beneficial both for themselves and for their students. When asked what they had learned through this event, the more technologicallysavvy teachers, Tom and Sara, talked about the benefits of video-conferencing and student interaction. Ed, on the other hand, only mentioned "knowledge about Canada's involvement in space research and development." Similarly, Tom and Sara mentioned "technological mishaps" and "too small visuals for the venue and audience size" as noted barriers in the viewed event; while Ed talked about students' discomfort during the event, busing costs, and lack of technology in schools (in one school, students were sitting on the gym floor during the event; schools without video-conferencing units bused their students to central video-conferencing locations).

The teachers' answers were also markedly different on other questions. Regarding main barriers for their personal ability to organize similar events, Tom mentioned: "funds to purchase [technology]; access to others with technology; room to share with others." Sara was more concerned about: "keeping high level of interest with visuals; matching material and topic with audiences; accommodating technician's requirements." For Ed, the major obstacles were: "mastering the technology to make something like this work; time needed to organize such event."

Of all three participant teachers, only Tom stated that after watching the video-conference-based event, he felt "somewhat" more willing to use integrated technology within his daily teaching. He felt that the "[high] cost of technology" and the "[lack of] access to video-conferencing people" would first need to be resolved. Sara felt that her experience with technology did not change by just watching the event (through video-conferencing unit), while Ed said that the organizers "did very little to convince me that this was a great learning experience." He also questioned why all the students were not brought to the large conference center where they could listen to the guest speaker instead. 


\section{Data Gathered From Pre-Service Teachers}

\section{Level of adoption of integrated technology}

The five pre-service teachers were volunteers from the third and fourth year of the JuniorIntermediate concurrent program at Nipissing University. The Figure 6 presents the pre-service teachers' positioning on the Stages of Adoption of Integrated Technologies Scale.

Initially, these pre-service teachers first self-identified themselves on the scale (two at level 2, one at level 3, and two at level 4). After that, they did the Attitude toward ICT questionnaire, watched the Canadian Space Agency learning event, and then joined the focus group discussion. Similarly, on the next two occasions, the participants watched another two events, followed by focus group meetings and evaluations of events.

The 6-level scale was conceptualized by the researchers as describing three increasing levels of adoption of technology, namely knowledge (about ICT), skill (in ICT use), and purposeful use (of ICT) as a teacher. Two pre-service teachers were at the knowledge level where they are still just learning about technology, while the other three pre-service teachers were at the skill level where they are getting familiarized with and gaining confidence in the use of ICT. None of the participants were at the level of purposeful use as a teacher, a fact that is understandable considering that, up to that point in time, they had not had much prior experience as practicing teachers.

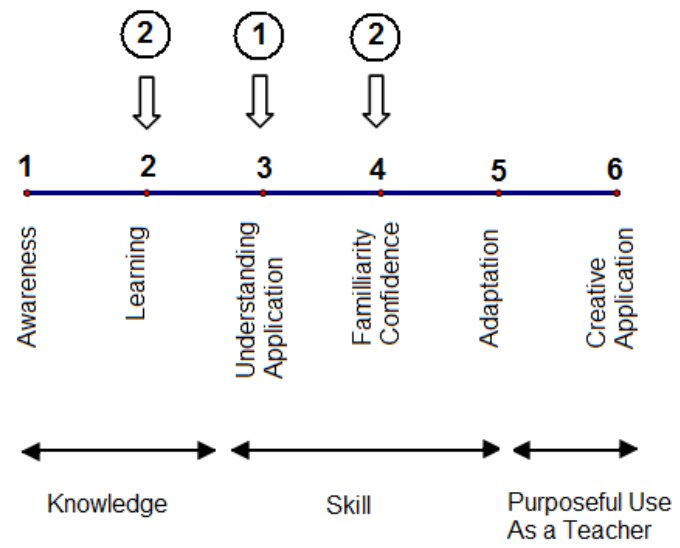

Figure 6. Positioning of five pre-service teachers on the Stages of Adoption of Integrated Technologies Scale.

\section{Perceived barriers and benefits in organizing ICT-enabled learning events}

The barriers and benefits noted by the pre-service teachers in the learning events are summarized in Table 1. They were categorized in respect to technology, organizational issues and pedagogical aspects.

Overall, the pre-service teachers' comments were mostly related to the pedagogy of technology use. For example, one of the pre-service participants noted the following pedagogical barriers to the organized learning events:

- Difficulty adhering to all learning styles/abilities

- Some of the kids were more engaged than others

- Shy students may avoid to get involved

- Short attention span among (especially younger) students. 
Table 1. Barriers and Benefits of the Video-Conferencing Events Noted By Pre-Service Teachers

\begin{tabular}{|c|c|c|c|}
\hline & TECHNOLOGY & ORGANIZATION & PEDAGOGY \\
\hline Barriers & $\begin{array}{l}\text {-Sound (quality, } \\
\text { volume, back- } \\
\text { ground noise) } \\
\text {-Equipment (lack } \\
\text { of, cost) } \\
\text {-Dependence (on } \\
\text { technology, connec- } \\
\text { tion) }\end{array}$ & $\begin{array}{l}\text {-Entire day/morning spent } \\
\text { on the event } \\
\text {-Dependence (on other } \\
\text { staff) } \\
\text {-Transition between sites } \\
\text {-Transportation between } \\
\text { sites } \\
\text {-Big participant groups }\end{array}$ & $\begin{array}{l}\text {-Lecture style of presentation } \\
\text {-Limited number of questions al- } \\
\text { lowed } \\
\text {-Not enough involvement of learners } \\
\text {-Difficult to keep students interested } \\
\text {-Younger grades have difficulty in } \\
\text { keeping up with older grades } \\
\text {-Students need to be ready for it }\end{array}$ \\
\hline Benefits & $\begin{array}{l}\text { Once technology is } \\
\text { available, the } \\
\text { events are cheaper } \\
\text { to organize }\end{array}$ & $\begin{array}{l}\text { MUTE feature is beneficial } \\
\text { during remote transitions }\end{array}$ & $\begin{array}{l}\text {-Students develop social skills (learn } \\
\text { to respect each others' opinions) } \\
\text {-Opportunity to ask questions } \\
\text {-Events may be cross-curricular } \\
\text {-Students take ownership of their } \\
\text { learning }\end{array}$ \\
\hline
\end{tabular}

For all five pre-service participants, the three most significant benefits of watching the events were:

- Seeing how such an activity/lesson works first-hand

- Seeing what worked and what may not have

- Seeing the timing/sequence of events.

The results of the questionnaires indicated that the pre-service teachers saw benefits in watching the broadcasted learning events and that, after doing so, they reported being more willing to use integrated technology within the classroom. However, one participant noted: "I'm worried that if the school I'm working in doesn't have the needed resources [then] travelling to other schools and such may not be an alternative."

\section{Perceived needs with respect to organizing ICT-enabled learning events}

The needs of in-service teachers necessary to enable them to organize similar video-conferencingbased learning events are presented in Figure 7. The needs that pre-service teachers envisioned to be satisfied in order to be able to organize such learning events themselves are given in Figure 8.

Comparatively, the needs of these two groups of teachers differed in several aspects. By watching videos of the events, the pre-service teachers could not see the events "through participants" eyes" and therefore had fewer requirements with respect to technology than those who were closely involved. 


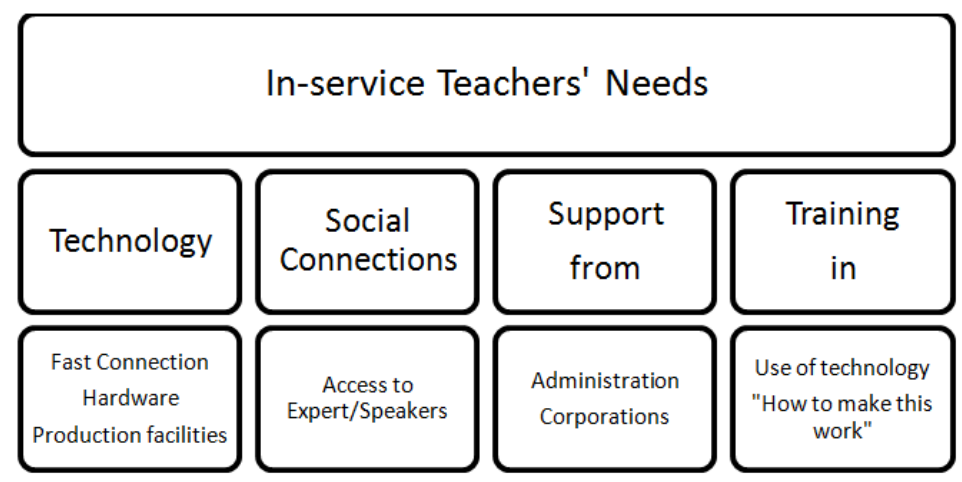

Figure 7. In-service teachers' needs for organizing video-conferencing learning events.

For, example, the pre-service teachers did not mention need for bigger screens and production facilities in schools (for good quality sound and light). On the other hand, the pre-service teachers perceived they would need more support from school staff and services, as well as from students and parents. Appearing fearful that what they would like to do in school may be too far from the established school norm, they would first want to make sure that necessary social support and approval are in place before embarking on the "technological adventure" they have observed. On the contrary, the in-service teachers seemed most concerned about not having all the technology or having outdated technology, finding ways to obtain support from corporations like Polycom, and the associated lack of training in "making things work."

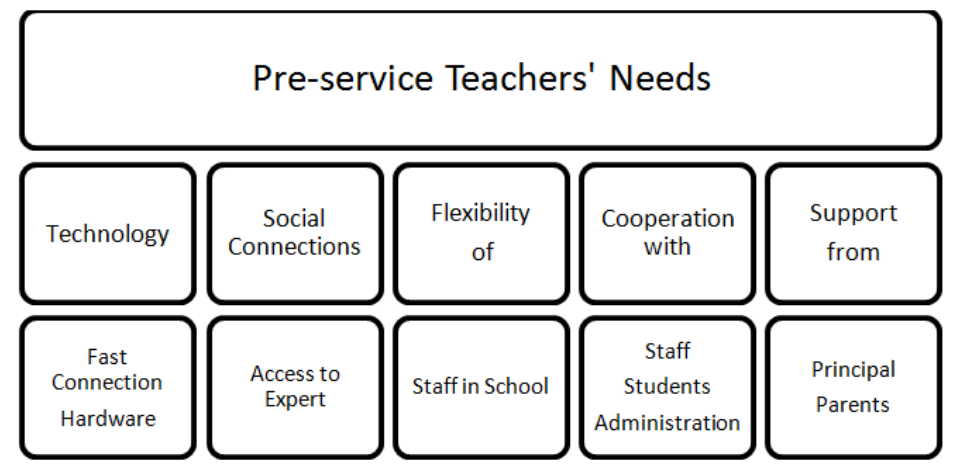

Figure 8. Pre-service students' needs for organizing video-conferencing learning events.

\section{Conclusions: What then is Effective Pedagogic Practice for Mobile, ICT-enabled Learning?}

In their 2002 paper, Zhao, Pugh, Sheldon, and Byers had invited readers to look into technology adoption from the perspective of school realities. They acknowledged "the messy process through which teachers struggle to negotiate a foreign and potentially disruptive innovation into their familiar environment" (2002, p. 483). Apparently, when considering the particulars in regard to the organization of ICT-enabled learning, specifically video-conference-based events, there are many barriers for teachers, both of an individuated and systemic nature. To a large extent, those who watched the video-taped footage (pre-service teachers in this study) only saw snapshots of the pedagogical organization. In order to further appreciate the associated complexity and "fill in the blanks" of their understanding, they needed more information and experience. For those without experience and technological skill, this process is particularly difficult. Initial, on-site, face-toface support for participant teachers, in regard to both the set-up of connective units and also to 
the associated technology training, is needed if one hopes to motivate and engage teachers to become active users of viable ICT-enabled learning tools.

Our preliminary findings suggest that there were marked differences between the individual inservice teachers' answers. In turn, we labeled them as "having a realist view of technology use." This view is based on the in-service teachers' knowledge of curricular processes and goals, in addition to having insiders' views of the results of student achievement from within school culture. Intriguingly, pre-service teachers showed a consistent unity amongst their answers. We labeled them as "having an idealist view of technology use." This view emerges from an outsider's position from which the culminating phases of the learning events involving video-conferencing technology were observed. Besides this limited insight, the only reference points afforded to these novices were related to their varied experiences during practice teaching. Thus, their view of the organization of video-conference-based learning events was idealistic.

The preliminary results of our study support the notion that in-service teachers who are in the initial stages of classroom-based technology use and who may, as a result, resist innovations (like Ed) can still change their attitudes. Such teachers need to be convinced that the emerging technologies could be beneficial for students' learning as they efficiently extend opportunities for learning and expand the social space of influence. Hammond et al. (2009) noted that becoming a very good user of ICT is something that is possibly informed and impacted by environmental factors. However, both Hammond et al. and this study accentuate the importance of the interaction between the individual and environment. In other words, the individual (pre-service or in-service teacher) needs to take a pro-active role in resolving pedagogical, organizational, and technological issues with respect to ICT adoption in school environment.

We speculate that besides the two obvious stages in the ICT development of teachers, namely idealist (prevalent during the study years) and realist (prevalent amongst teacher-practitioners), there is another, highly sought position of a realistic-idealist. Those who reach this stage of professional development have both the realist view of the system, as well as the working knowledge of pedagogy, yet they are idealistically willing to experiment with innovative technologies for the benefit of student learning. The necessary prerequisites for such a process seem to be the provision of high-quality, powerful, and convincing examples of ICT use in subject teaching (Barton \& Haydn, 2006) which go beyond ICT skills (Hughes, 2005) and link to the development of wider pedagogical knowledge (Hammond et al., 2009).

Our goal is, therefore, to develop strategic interventions that will serve two purposes: (1) to help technological idealists to obtain the realistic-insider view on pedagogy involved in the use of ICT-embedded technology within learning; and, (2) to help technological realists to take ownership over the idealistic push toward novel application of technology within education, despite the very real barriers inherent to the process. It is our hope that such efforts will inform current practice such that the use of ICT-enabled learning becomes more the norm and less of the exception within the daily classroom.

\section{Future Work}

As we look to the future of our journey toward the further integration of mobile ICT-enabled learning events within best pedagogical practice, we recognize the necessity of focusing our interventionist efforts upon the creation of a "common ground" for all educational stakeholders. It is upon this common ground that researchers, teachers, and students can collaborate in a mutually cohesive forum that will, in turn, give rise to the development of a realistic-idealist view of embedded-ICT use within daily education. Thus, we provide our own current experiences, which serve as modeled exemplars for others who will follow our path towards creating their own mobile ICT-enabled events. This may encourage our readers to take on the characteristics of realis- 
tic-idealists - those who see learning with and through technology as necessarily appropriate, responsive, engaging, and effective for current generations of students.

\section{References}

Barton, R., \& Haydn, T. (2006). Trainee teachers' views on what helps them to use information and communication technology effectively in their subject teaching. Journal of Computer Assisted Learning, 22(4), 257-272.

Christensen, R. (1997). Effect of technology integration education on the attitudes of teachers and their students. Doctoral dissertation, Univ. of North Texas.

Cousins, J. B., \& Leithwood, K. A. (1993). Enhancing knowledge utilization as a strategy for school improvement. Knowledge: Creation, Diffusion, Utilization, 14(3), 305-333.

Cousins, J. B., \& Simon, M. (1996). The nature and impact of policy-induced partnerships between research and practice communities. Educational Evaluation and Policy Analysis, 18(3), 199-218.

Cuthell, J. P. (2006). Steering the supertanker: Transforming teaching and learning through the use of ICT. Computers in the Schools, 23(1/2), 99-110.

Cycon, H. L., Schmidt, T. C., Hege, G., Wählisch, M., \& Palkow, M. (2009). Let's meet at the mobile Learning dialogs with a video conferencing software for mobile devices. International Journal of Interactive Mobile Technologies (iJIM), 3(3), 21-25.

Griffin, D., \& Christensen, R. (1999). Concerns-Based Adoption Model (CBAM) Levels of Use of an Innovation (CBAM-LOU). Denton, Texas: Institute for the Integration of Technology into Teaching and Learning.

Hammond, M., Crosson, S., Fragkouli, E., Ingram, J., Johnston-Wilder, P., Johnston-Wilder, S., Kingston, Y., Pope, M., \& Wray, D. (2009). Why do some student teachers make very good use of ICT? An exploratory case study. Technology, Pedagogy and Education, 18(1), 59 - 73.

Huberman, M. (1989). Predicting conceptual effects in research utilization: Looking with both eyes. Knowledge in Society, 2(3), 6-24.

Hughes, M. (2005). Reach to teach ICT: Issues and compromises. Education and Information Technologies, 10(3), 263-276.

Knezek, G., Christensen, R., Miyashita, K., \& Ropp, M. (2000). Instruments for assessing educator progress in technology integration. Denton, TX: University of North Texas. Retrieved August 15, 2005 from http://www.iittl.unt.edu

Laouris, Y., \& Eteokleous, N. (2005). Proceedings of the 4th World Conference on Mobile Learning. Cape Town, South Africa. Retrieved March 12, 2010 from http://www.mlearn.org.za/CD/papers/Laouris \& Eteokleous.pdf

Martinovic, D., Magliaro, J., \& Pugh, T. (2009). Applying emerging technologies to build communities of collaborative learning. In A. Méndez-Vilas, A. Solano Martín, J.A. Mesa González and J. Mesa González (Eds.), Research, Reflections and Innovations in Integrating ICT in Education (Vol. 2, pp. 917921). Badajoz, Spain: Formatex. Retrieved March 1, 2010 from http://www.formatex.org/micte2009/book/917-921.pdf

Milrad, M. (2003). Mobile learning: Challenges, perspectives, and reality. In K. Nyiri (Ed.), Mobile learning essays on philosophy, psychology and education (pp. 151-164). Vienna: Passagen Verlag.

Nyiri, K. (2002). Towards a philosophy of m-learning. IEEE International Workshop on Wireless and Mobile Technologies in Education (WMTE 2002), August 29-30, 2002, Teleborg Campus.

The Ontario Curriculum, Grades 1-8: Science and Technology. (2007). Retrieved August 27, 2010 from http://www.edu.gov.on.ca/eng/curriculum/elementary/scientec18currb.pdf 
Polsani, P. (2003). Network learning. In K. Nyiri (Ed.), Mobile learning essays on philosophy, psychology and education (pp. 139-150). Vienna: Passagen Verlag.

Punie, Y. (2007). Learning spaces: An ICT-enabled model of future learning in the knowledge-based society. European Journal of Education, 42(2), 185-199.

Sharples, M. (2005). Learning as conversation: Transforming education in the mobile age. Paper presented at Conference on Seeing, Understanding, Learning in the Mobile Age, Budapest, Hungary, April 2005. Retrieved March 1, 2010 from http://www.fil.hu/mobil/2005/Sharples final.pdf

Sharples, M., Taylor, J., \& Vavoula, G. (2005). Towards a theory of mobile learning. Proceedings of mLearn 2005 Conference, Cape Town. Retrieved December 5, 2009 from http://www.mlearn.org.za/CD/papers/Sharples.pdf

Zhao, Y., Pugh, K., Sheldon, S., \& Byers, J. L. (2002). Conditions for classroom technology innovations. Teachers College Record, 104(3), 482-515.

\section{Appendix A: Culminating Task for Air and Flight Science: Grade 6 (2008)}

\section{Instructions for Students}

For this unit's culminating activity, you must create a device that will safeguard the payload, a raw egg, from breakage after being dropped from a height of 2.5 meters.

This device must incorporate and build upon your knowledge and understanding of the properties of air and principles of flight that we have examined throughout this unit.

The following is a list of the core concepts that must be addressed during the construction of your device:

Bernoulli's Principle / Drag / Gravity /Compression/ Aerodynamics / Pitch / Yaw/ Pressure Each group will be given a basket of materials. Each basket contains exactly the same amount and type of materials. Groups will have to construct their device using ONLY the materials found in their respective baskets. While groups do not have to use ALL of their materials, it is strongly recommended that a plan be put into place BEFORE construction begins!

Each group will be allowed to go DUMPSTER DIVING three times throughout the construction process in order to meet any difficulties in construction needs. On each dumpster dive, one member of each group will be allowed to "dive in and choose" ONE extra object that is necessary for their device's success. Once this object is chosen, it cannot be chosen again.

\section{Organizational Instructions}

1) Choose a construction/work station.

2) Assign the following roles to your group members:

- Egg-handler/messenger

- Engineer/planner

- Quality control/payload inspector

** These roles are roles of responsibility only!

** The domination of team members by one person will not be tolerated!

** All team members must work together in order to achieve success!

3) Ensure that your group has the following items before your teacher starts the activity: 
- A copy of these instructions

- A copy of your CT rubric

- A basket of materials

- 3 pieces of blank $8.5 \times 11$ " paper

- 1 piece of blank $8.5 \times 14 "$ paper

- 1 piece of blank $8.5 \times 17$ " paper

- Pencils, erasers, pencil crayons, markers, hi-liters, rulers, math set.

\section{Working Instructions: Stage \#1 - Planning}

1) Read through all of the working instructions before starting your activity.

2) Examine the CT rubric and decide which completion level you are targeting as a group. hi-lite the completion levels in each area.

3) Divide one of the $8.5 \times 11$ " papers into three equal sections and brainstorm 3 different device construction ideas. In each section, use words, and/or pictures to communicate your ideas.

4) As a group, decide which construction idea is the best and create a working blueprint of this device. The blueprint must be accurate and neat, displaying both the proper measuring techniques and the use of appropriate scientific vocabulary. It must also align with the CT rubric.

5) Once your group's blueprint is complete, entitle it: "Final Working Blueprint" (include all of your names on it) and then bring it to your teacher for an initial before beginning the actual construction.

\section{Working Instructions: Stage \#2-Construction}

1) Construct your device, following your construction blueprint as closely as possible. If, during the construction process, you find that you need to change your device slightly from your working blueprint, then simply draw in the changes on your blueprint, using a red pencil crayon or marker.

2) Your egg handler may ask to "borrow" your raw egg once during the construction process in order to get your device ready ("test-fit") to receive the payload. You must return the raw egg to the carton as soon as your "test-fit" is done.

3) Once you are certain that all is ready, then your egg-handler can return to get your raw egg. Once your egg is retrieved the second time, then it must stay with your group and be integrated into your device.

** If your raw egg breaks before stage \#3, then your group will be disqualified.

\section{Working Instructions: Stage \#3-Testing}

1) When your device is complete, you must notify your teacher. He will initial your CT rubric to signify your successful completion of Stage \#2.

2) Spend some time looking over your CT rubric, ensuring that you have covered all of your targeted level criteria.

3) Prepare a short report with the following information:

- A point-form description of the most important features of your device.

- A point-form list of all of the challenges that you experienced during Stages \# $1 \& 2$ of this activity.

- A list of burning questions that you wish to ask regarding your device. 
4) Observe the test drop and record your results on your CT rubric

5) Collect the following for submission, ensuring that ALL names of team members are present:

- Brainstorming idea page (3 sections)

- Final working blueprint

- CT rubric with teacher's initials

- Written report.

\section{Appendix B: Organization of the Canadian Space Agency Learning Event}

\section{Instructions for Participating Sites}

12:15-12:30 pm -- participants gather at all sites

12:30-12:45 pm -- final testing \& establishment of connection

**all sites on mute

12:45 - 12:50 pm - Site 1 goes live \& off mute

- Opening remarks and welcome to all participants to event [remote site moderators to be called in turn for sound check]

- Acknowledgements of event partners, students and the Board staff

** All remote sites unmute \& wave to each other in this order:

- Site 2; Site 3; Site 4

**All remote sites mute again/All remote sites mute except for Site 1

- Introduction of guest speaker (brief bio \& welcome)

12:50 - 1:10 pm -- guest speaker's presentation

1:10 - 1:15 pm ** instructions to students at Site 1

** All remote sites mute except for Site 1

1:15-1:30 pm: open mic between the expert and students at Site 1

** All remote sites mute except for Site 1

1:30 - 1:45 pm: ** instructions to students at Site 2

Open mic between the expert and elementary students at Site 2

** All remote sites mute except for Site 1 and Site 2

1:45 - 2:00 pm: ** instructions for students at Site 3

Open mic between Site 1 and students at Site 3

**All remote sites mute except for Site 1 and Site 3

2:00 - 2:15 pm: ** instructions for students at Site 4

Open mic between Site 1 and students at Site 4

** All remote sites mute except for Site 1 and Site 4 
2:15 - pm ** thanks to speaker on behalf of all remote sites-elementary students

** All remote sites unmute and clap/acknowledge speaker

** All elementary students begin to leave

** All remote sites mute except for Site $1 \&$ Site 2

2:15-2:30 pm ** instructions for students

Open mic between the expert and secondary students at Site 2

2:30 pm ** closing and thank you.

\section{Biographies}

Dragana Martinovic, Ph.D., M.Sc. is an Associate Professor at the Faculty of Education. Her research interests stem from her multidisciplinary background and encompass mathematics, computer science and education. Dragana's research is focused on Internet-based systems, including integration of connective and collaborative technologies in education, cyberethics, privacy, as well as cognitive, emotional, and attitudinal factors in human-computer interaction.

Mr. Timothy Pugh, one of the Coordinating Teachers of Virtual Grand E Communication Literacy Project, currently fulfills two positions within Grand Erie District School Board: (1) Junior/Intermediate rotary specialty teacher; and (2) Special Assignment Teacher for ICT. He is also an adjunct professor at Nipissing University - Brantford's Faculty of Education where he instructs fourth-year pre-service teacher candidates in Science and Technology. In addition, he serves as an ICT Resource Teacher for his school site. His current research is focused upon the development of best practice methodologies within the area of ICT through the metacognitive construct of Communication Literacy.

Dr. Jelena Magliaro is an employee at the University of Windsor. Her academic background in computer science, psychology and education has influenced her research interests, focusing on the role of technology integration in teaching and learning. Dr. Magliaro is also promoting open access of academic writing and publishing. Her current research is in information literacy, focusing specifically on how educators can better disseminate research knowledge to students at all levels.

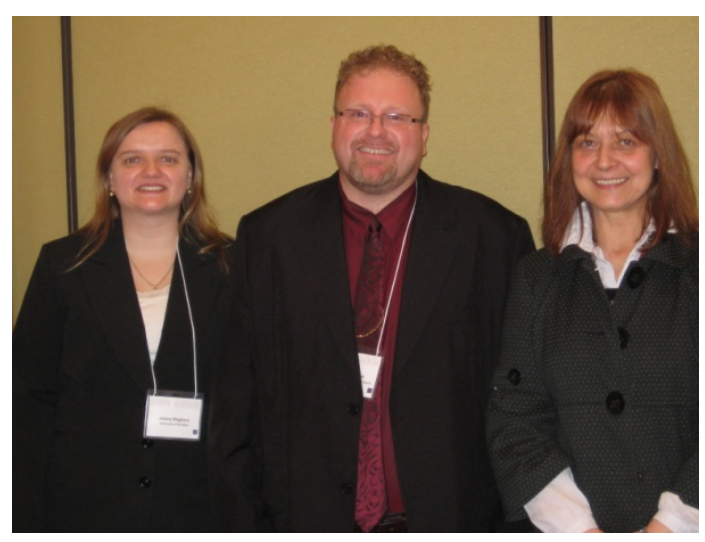

From left to right: Magliaro, Pugh and Martinovic 